\title{
Additional cucurbitane glycosides from Siraitia grosvenorii
}

\author{
Venkata Sai Prakash Chaturvedula*, Indra Prakash \\ The Coca-Cola Company, Organic Chemistry Department, Global Research and Development, \\ One Coca-Cola Plaza, Atlanta, GA 30313, USA
}

\begin{abstract}
Continuation of the phytochemical studies of the extract of Luo Han Go (Siraitia grosvenorii) furnished two additional known cucurbitane glycosides namely mogroside III A2, and 11-deoxymogroside III. The structures of the two isolated compounds 1-2 were characterized and their complete ${ }^{1} \mathrm{H}$ and ${ }^{13} \mathrm{C}$ NMR spectral assignments were made based on COSY, HMQC, HMBC and NOESY spectroscopic data, hydrolysis studies and in comparison with literature data.
\end{abstract}

Keywords-Siraitia grosvenorii, Cucurbitaceae, Luo Han Go, Cucurbitane glycosides, NMR, MS, Chemical studies

\section{INTRODUCTION}

The fruit of Siraitia grosvenorii (Swingle) Lu \& Zhang (Momordica grosvenorii; Cucurbitaceae) is used as an expectorant and as a natural sweetener which grows widely in Guangxi, People's Republic of China [1-3]. The fruit of S. grosvenorii, also known as Luo Han Guo, has been used for centuries in traditional Chinese medicine for the treatment of pulmonary demulcent and emollient for the treatment of dry cough, sore throat, and constipation [4]. Luo Han Guo is well known now throughout the world due to its intense sweet taste and has been used as a non-caloric natural sweetener in some countries. Early chemical investigation revealed that the sweet principles of Luo Han Guo were triterpenoid glycosides also known as mogrosides [1-4]. In continuation of our study on the isolation of natural sweeteners from the commercial extracts of various sweet taste plants, we have recently reported isolation and characterization of several diterpene glycosides from $S$. rebaudiana [5-12], cucurbitane glycosides namely mogroside IVa, mogrosides V \& VI, isomogroside V, 11oxomogroside $\mathrm{V}$ and siamenoside I apart from the two phenolic glycosides namely kaempferol-3- $O-\alpha-\mathrm{L}-$ rhamnoside and kaempferol-3,7-O- $\alpha$-L-dirhamnoside from the aqueous alcoholic extract of Luo Han Go extract [13-14] based on their extensive NMR and Mass spectroscopic studies. In this paper we are describing the isolation and structure elucidation of the two additional cucurbitane glycosides, mogrosides III A2 (1), and 11deoxymogroside III (2) that were characterized on the basis of COSY, HSQC, HMBC and NOESY spectral data as well as chemical studies (Figure 1).

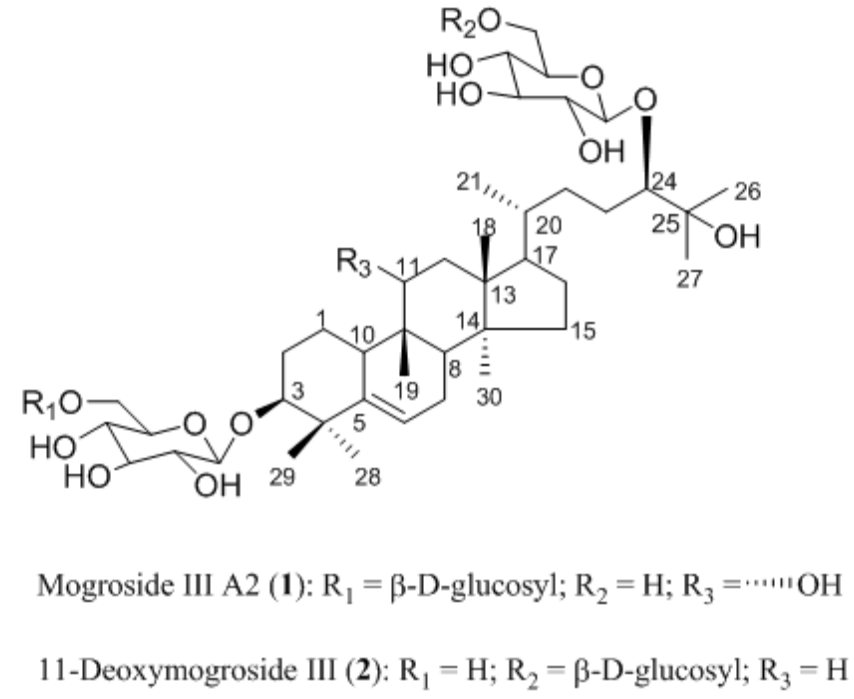

Figure 1: Structures of Mogroside III A2 (1) and 11-Deoxymogroside III (2) 


\section{General Methods}

\section{MATERIALS AND METHODS}

NMR spectra were acquired on a Varian Unity Plus $600 \mathrm{MHz}$ instrument using standard pulse sequences at ambient temperature. Chemical shifts are given in $\delta(\mathrm{ppm})$, and coupling constants are reported in Hz. MS and MS/MS data were generated with a Waters Premier Quadrupole Time-of-Flight (Q-Tof) mass spectrometer equipped with an electrospray ionization source operated in the positive-ion mode and ThermoFisher Discovery OrbiTrap in the positive Positive Mode Electrospray. Samples were diluted with water: acetonitrile (1:1) containing $0.1 \%$ formic acid and introduced via infusion using the onboard syringe pump at $\sim 10 \mathrm{ul} / \mathrm{min}$. Low pressure chromatography was performed on a Biotage Flash system using a C-18 cartridge $(40+\mathrm{M}, 35-70 \mu \mathrm{m})$. TLC was performed on Baker $\mathrm{Si}_{-} \mathrm{C}_{18} \mathrm{~F}$ plates with mobile phase $\mathrm{H}_{2} \mathrm{O}-\mathrm{MeOH}$ (35:65). Identification of the spots on the TLC plate was carried out by spraying $10 \% \mathrm{H}_{2} \mathrm{SO}_{4}$ in $\mathrm{EtOH}$ and heating the plate at about $80^{\circ} \mathrm{C}$. Analytical HPLC for sugar analysis was carried out with a Waters $600 \mathrm{E}$ multisolvent delivery system using a Phenomenex Luna $C_{18}$ non-chiral $(150$ x $4.6 \mathrm{~mm}, 5 \mu \mathrm{m})$ column.

\section{Materials}

The Luo Han Guo commercial extract was purchased from Chengdu Biopurify Phytochemicals, China. A voucher specimen is deposited at The Coca Cola Company, No. VSPC-3166-99.

\section{Isolation and Purification}

The Luo Han Guo extract ( $50 \mathrm{~g}$ ) was purified on a C-18 column using a Biotage Flash chromatography system (Solvent system: gradient from 20-80\% MeOH-water, $60 \mathrm{~mL} / \mathrm{min}$, Detection: UV $210 \mathrm{~nm}$ ) by collecting 60 fractions. Fractions 39-43 (1.2 g) were combined and subjected to repeated Flash Chromatography purification with gradient from $60-40 \% \mathrm{MeOH}$-water, $30 \mathrm{~mL} / \mathrm{min}$ afforded mogroside III A2 (1, $80 \mathrm{mg})$. Fractions 44-48 $(2.1 \mathrm{~g})$ were combined and further subjected by Flash Chromatography purification two times (Solvent system: 70\% MeOH-water, $20 \mathrm{~mL} / \mathrm{min}$, Detection: UV $210 \mathrm{~nm}$ ) yielded the 11-deoxymogroside III (2, $46 \mathrm{mg}$ ).

General procedure for acid hydrolysis and determination of sugar configuration.

Each glycoside 1-2 $(1 \mathrm{mg})$ was hydrolyzed with $0.5 \mathrm{M} \mathrm{HCl}(0.5 \mathrm{~mL})$ for $1.5 \mathrm{~h}$. After cooling, the mixture was passed through an Amberlite IRA400 column and the eluate was lyophilized. The residue was dissolved in pyridine $(0.25 \mathrm{~mL})$ and heated with L-cysteine methyl ester $\mathrm{HCl}(2.5 \mathrm{mg})$ at $60^{\circ} \mathrm{C}$ for $1.5 \mathrm{~h}$, and then $O$-tolyl isothiocyanate $(12.5 \mathrm{uL})$ was added to the mixture and heated at $60^{\circ} \mathrm{C}$ for an additional $1.5 \mathrm{~h}$. The reaction mixture was analyzed by HPLC: column Phenomenex Luna $\mathrm{C}_{18}, 150$ x $4.6 \mathrm{~mm}(5 \mathrm{u}) ; 25 \%$ acetonitrile$0.2 \%$ TFA water, $1 \mathrm{~mL} / \mathrm{min}$; UV detection at $250 \mathrm{~nm}$. The sugar was identified as D-glucose in each experiment $(t \mathrm{R}, 12.25$ to $12.36 \mathrm{~min})$ [authentic samples, D-glucose $(t \mathrm{R}, 12.34)$ and L-glucose $(t \mathrm{R}, 11.12 \mathrm{~min})$ ] [15].

\section{RESULTS AND DISCUSSION}

Purification of the commercial extract of Luo Han Guo (S. grosvenorii) resulted in the isolation of two additional cucurbitane glycosides 1-2, which were identified as mogrosides III A2, and 11-deoxymogroside III. The structures of the two compounds were characterized from the detailed spectroscopic studies (COSY, HMQC, HMBC and NOESY) as well chemical studies, and in comparison of their spectral data with the reported values in the literature [16].

Compound 1, was obtained as a white powder. The molecular formula was inferred as $\mathrm{C}_{48} \mathrm{H}_{82} \mathrm{O}_{19}$ from MS studies. The ESI-MS spectrum of this compound was found at $\mathrm{m} / \mathrm{z} 961$ to correspond to [M-H] quasimolecular ion, suggesting that the molecular weight of compound $\mathbf{1}$ is 962 . The ${ }^{1} \mathrm{H}$ NMR spectrum of $\mathbf{1}$ showed the presence of seven methyl singlets at $\delta 0.89,0.90,1.15,1.34,1.47,1.50$, and 1.57 , a methyl doublet at 1.06, eight methylene and seven methine groups between $\delta$ 1.15-3.86 (including three secondary hydroxyl groups), and a tertiary hydroxyl resonating at $\delta_{\mathrm{C}} 72.8$; characteristic to the aglycone moiety of the triterpenoid mogrol isolated earlier from S.grosvenorii. The ${ }^{1} \mathrm{H}$ NMR spectrum of $\mathbf{1}$ also showed the presence three anomeric protons as doublets at $\delta 4.96,5.11$ and 5.35 suggesting the presence of three hexose moieties which was

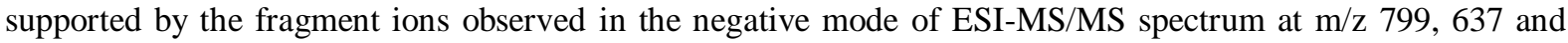
475. Acid hydrolysis of $\mathbf{1}$ afforded a hexose unit that was identified as glucose and its configuration was confirmed as D-glucose by preparing the corresponding thiocarbamoyl-thiazolidine carboxylate derivative with L-cysteine methyl ester and $O$-tolyl isothiocyanate, and in comparison of its retention time with the standard sugars as described in the literature [15]. The ${ }^{1} \mathrm{H}$ and ${ }^{13} \mathrm{C}$ NMR values for all the protons and carbons were assigned on the basis of COSY, HMQC and HMBC correlations and were given in Tables 1-2. 
Additional cucurbitane glycosides from siraitia grosvenorii

Table 1: ${ }^{1} \mathrm{H}$ NMR chemical shifts values for the compounds $\mathbf{1 - 2}$ in $\mathrm{C}_{5} \mathrm{D}_{5} \mathrm{~N}^{\mathrm{a}-\mathrm{c}}$

\begin{tabular}{|c|c|c|}
\hline Proton & 1 & 2 \\
\hline 1 & $1.48 \mathrm{~m}, 1.96 \mathrm{~m}$ & $1.46 \mathrm{~m}, 1.84 \mathrm{~m}$ \\
\hline 2 & $1.93 \mathrm{~m}, 2.42 \mathrm{~m}$ & $1.93 \mathrm{~m}, 2.43 \mathrm{~m}$ \\
\hline 3 & 3.45 br s & 3.64 br $\mathrm{s}$ \\
\hline 6 & $5.49 \mathrm{~d}(6.2)$ & $5.47 \mathrm{~d}(6.2)$ \\
\hline 7 & $1.81 \mathrm{~m}, 2.35 \mathrm{~m}$ & $1.83 \mathrm{~m}, 2.23 \mathrm{~m}$ \\
\hline 8 & 1.65 br s & 1.63 br $\mathrm{s}$ \\
\hline 10 & $2.48 \mathrm{~d}(12.4)$ & $2.26 \mathrm{~d}(12.1)$ \\
\hline 11 & $3.86 \mathrm{~m}$ & $1.34 \mathrm{~m}, 1.62 \mathrm{~m}$ \\
\hline 12 & $1.82 \mathrm{~m}, 1.86 \mathrm{~m}$ & $1.43 \mathrm{~m}, 1.58 \mathrm{~m}$ \\
\hline 15 & $1.15 \mathrm{~m}, 1.20 \mathrm{~m}$ & $1.12 \mathrm{~m}, 1.20 \mathrm{~m}$ \\
\hline 16 & $1.33 \mathrm{~m}, 1.98 \mathrm{~m}$ & $1.42 \mathrm{~m}, 2.06 \mathrm{~m}$ \\
\hline 17 & $1.63 \mathrm{~d}(9.1)$ & $1.58 \mathrm{~d}(9.1)$ \\
\hline 18 & $0.89 \mathrm{~s}$ & $0.86 \mathrm{~s}$ \\
\hline 19 & $1.50 \mathrm{~s}$ & $0.89 \mathrm{~s}$ \\
\hline 20 & $1.44 \mathrm{~m}$ & $1.48 \mathrm{~m}$ \\
\hline 21 & $1.06 \mathrm{~d}(6.2)$ & $0.97 \mathrm{~d}(6.0)$ \\
\hline 22 & $1.51 \mathrm{~m}, 1.58 \mathrm{~m}$ & $1.72 \mathrm{~m}, 1.86 \mathrm{~m}$ \\
\hline 23 & $1.85 \mathrm{~m}$ & $1.80 \mathrm{~m}, 1.88 \mathrm{~m}$ \\
\hline 24 & $3.40 \mathrm{~m}$ & 3.72 br d (9.8) \\
\hline 26 & $1.47 \mathrm{~s}$ & $1.45 \mathrm{~s}$ \\
\hline 27 & $1.34 \mathrm{~s}$ & $1.37 \mathrm{~s}$ \\
\hline 28 & $1.15 \mathrm{~s}$ & $1.12 \mathrm{~s}$ \\
\hline 29 & $1.57 \mathrm{~s}$ & $1.54 \mathrm{~s}$ \\
\hline 30 & $0.90 \mathrm{~s}$ & $0.88 \mathrm{~s}$ \\
\hline \multicolumn{3}{|c|}{ Glucose-1 } \\
\hline 1 & $5.11 \mathrm{~d}(7.2)$ & $5.04 \mathrm{~d}(7.5)$ \\
\hline 2 & $4.04 \mathrm{~m}$ & $3.91 \mathrm{~m}$ \\
\hline 3 & $4.21 \mathrm{~m}$ & $4.22 \mathrm{~m}$ \\
\hline 4 & $3.94 \mathrm{~m}$ & $4.10 \mathrm{~m}$ \\
\hline 5 & $4.08 \mathrm{~m}$ & $3.90 \mathrm{~m}$ \\
\hline 6 & $3.98 \mathrm{~m}, 4.92 \mathrm{~m}$ & $4.38 \mathrm{~m}, 4.56 \mathrm{~m}$ \\
\hline \multicolumn{3}{|c|}{ Glucose-2 } \\
\hline 1 & $4.96 \mathrm{~d}(7.4)$ & $4.98 \mathrm{~d}(7.6)$ \\
\hline 2 & $4.04 \mathrm{~m}$ & $4.02 \mathrm{~m}$ \\
\hline 3 & $4.18 \mathrm{~m}$ & $4.17 \mathrm{~m}$ \\
\hline 4 & $4.32 \mathrm{~m}$ & $3.98 \mathrm{~m}$ \\
\hline 5 & $3.90 \mathrm{~m}$ & $4.12 \mathrm{~m}$ \\
\hline 6 & $4.14 \mathrm{~m}, 4.36 \mathrm{~m}$ & $3.95 \mathrm{~m}, 4.88 \mathrm{~m}$ \\
\hline \multicolumn{3}{|c|}{ Glucose-3 } \\
\hline 1 & $5.35 \mathrm{~d}(7.6)$ & $4.86 \mathrm{~d}(7.4)$ \\
\hline 2 & $4.03 \mathrm{~m}$ & $4.01 \mathrm{~m}$ \\
\hline 3 & $4.26 \mathrm{~m}$ & $4.24 \mathrm{~m}$ \\
\hline 4 & $4.34 \mathrm{~m}$ & $4.30 \mathrm{~m}$ \\
\hline 5 & $3.93 \mathrm{~m}$ & $3.85 \mathrm{~m}$ \\
\hline 6 & $4.16 \mathrm{~m}, 4.38 \mathrm{~m}$ & $4.22 \mathrm{~m}, 4.46 \mathrm{~m}$ \\
\hline
\end{tabular}

Chemical shift values are in $\delta(\mathrm{ppm})$. 
Additional cucurbitane glycosides from siraitia grosvenorii

Table 2: ${ }^{13} \mathrm{C}$ NMR chemical shift values $(\delta, \mathrm{ppm})$ for the compounds 1-2 in $\mathrm{C}_{5} \mathrm{D}_{5} \mathrm{~N}^{\mathrm{a}}$

\begin{tabular}{|c|c|c|}
\hline Carbon & 1 & 2 \\
\hline 1 & 27.2 & 27.3 \\
\hline 2 & 29.9 & 29.4 \\
\hline 3 & 88.4 & 88.2 \\
\hline 4 & 42.7 & 41.8 \\
\hline 5 & 144.7 & 143.4 \\
\hline 6 & 118.9 & 118.7 \\
\hline 7 & 25.0 & 24.9 \\
\hline 8 & 43.9 & 44.0 \\
\hline 9 & 40.5 & 34.6 \\
\hline 10 & 37.1 & 38.2 \\
\hline 11 & 77.0 & 32.6 \\
\hline 12 & 41.4 & 30.5 \\
\hline 13 & 47.8 & 46.9 \\
\hline 14 & 50.1 & 49.2 \\
\hline 15 & 34.9 & 34.9 \\
\hline 16 & 28.9 & 28.0 \\
\hline 17 & 51.3 & 51.3 \\
\hline 18 & 17.5 & 17.6 \\
\hline 19 & 26.7 & 28.2 \\
\hline 20 & 37.2 & 36.4 \\
\hline 21 & 19.7 & 19.0 \\
\hline 22 & 34.2 & 33.3 \\
\hline 23 & 29.9 & 30.0 \\
\hline 24 & 92.4 & 92.6 \\
\hline 25 & 72.8 & 72.8 \\
\hline 26 & 26.3 & 24.2 \\
\hline 27 & 21.9 & 26.9 \\
\hline 28 & 28.0 & 28.4 \\
\hline 29 & 27.2 & 26.1 \\
\hline 30 & 19.5 & 18.1 \\
\hline \multicolumn{3}{|c|}{ Glucose-1 } \\
\hline 1 & 107.8 & 107.5 \\
\hline 2 & 75.7 & 75.7 \\
\hline 3 & 78.2 & 78.6 \\
\hline 4 & 71.4 & 71.7 \\
\hline 5 & 76.3 & 78.3 \\
\hline 6 & 70.0 & 63.1 \\
\hline \multicolumn{3}{|c|}{ Glucose-2 } \\
\hline 1 & 106.8 & 106.5 \\
\hline 2 & 75.3 & 75.3 \\
\hline 3 & 78.2 & 78.7 \\
\hline 4 & 71.7 & 71.9 \\
\hline 5 & 78.2 & 76.7 \\
\hline 6 & 62.8 & 70.6 \\
\hline \multicolumn{3}{|c|}{ Glucose-3 } \\
\hline 1 & 102.3 & 104.8 \\
\hline 2 & 75.3 & 75.5 \\
\hline 3 & 78.8 & 78.0 \\
\hline 4 & 71.7 & 71.5 \\
\hline 5 & 78.4 & 78.5 \\
\hline 6 & 62.9 & 62.7 \\
\hline
\end{tabular}

${ }^{a}$ Assignments were made on the basis of COSY, HMQC and HMBC 
The placement of the three sugar units in $\mathbf{1}$ was confirmed as a $1 \rightarrow 6 \beta$-D-glucobiosyl substituent at C-3 with an additional $\beta$-D-glucosyl unit at C-24 position on the basis of the key HMBC and NOESY correlations as shown in Figure 2. A close comparison of the NMR spectral data of $\mathbf{1}$ with the reported literature values for mogroside III A2 confirmed its structure [16].

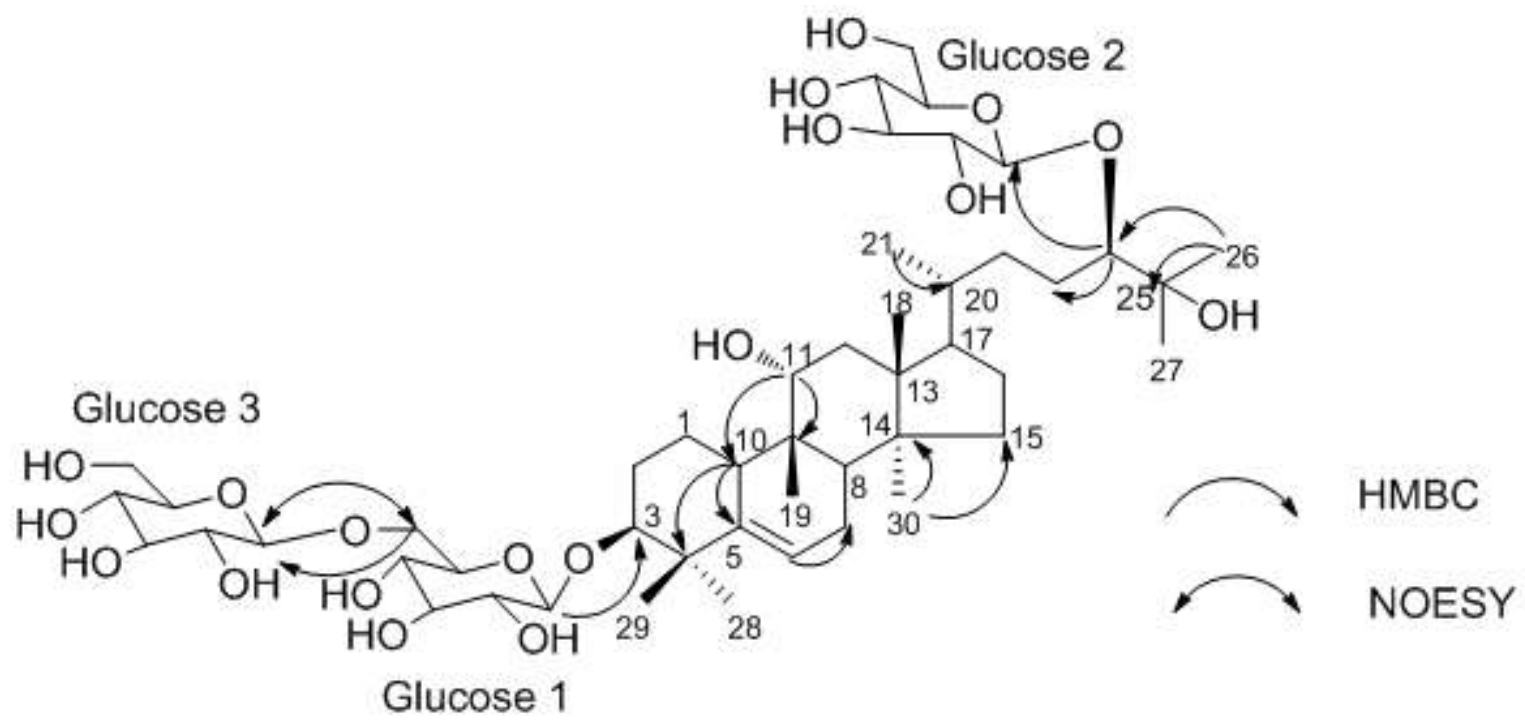

Figure 2: Key HMBC and NOESY correlation of Mogroside III A2 (1)

Compound 2 was also obtained as a white amorphous powder and its molecular formula was inferred as $\mathrm{C}_{48} \mathrm{H}_{82} \mathrm{O}_{18}$ from the ESI-MS/MS spectrum. A peak at $\mathrm{m} / \mathrm{z} 945$ corresponding to [M-H] in the ESI-MS spectrum, suggested that the molecular weight of compound 2 might be 946 . The ${ }^{1} \mathrm{H}$ NMR spectrum of 2 showed the presence of seven methyl singlets, one methyl doublet, eight methylenes and seven methines, identical to $\mathbf{1}$. The ${ }^{1} \mathrm{H}$ NMR spectrum of $\mathbf{2}$ showed the presence three anomeric protons suggesting the presence of three hexose moieties and acid hydrolysis confirmed the sugar and its stereochemistry as D-glucose. A close comparison of the ${ }^{1} \mathrm{H}$ and ${ }^{13} \mathrm{C}$ NMR chemical shift values of $\mathbf{1}$ and $\mathbf{2}$ together with their ESI-MS data which has 16 amu difference suggested the absence of the hydroxyl group at C-11 position which was supported by the presence of two secondary hydroxyl groups in its aglycone part from the ${ }^{1} \mathrm{H}$ and ${ }^{13} \mathrm{C}$ NMR spectral data (Tables 1 and 2). The three $\beta$-D-glucosyl moieties were present as $1 \rightarrow 6$ linked $\beta$-D-glucobiosyl substituent at C-24 with an additional $\beta$-D-glucosyl moiety at C-3 were identified on the basis of the key HMBC and NOESY correlations as shown in Figure 3. The ${ }^{1} \mathrm{H}$ and ${ }^{13} \mathrm{C}$ NMR spectral data (Tables 1-2) for compound 2 were assigned based on the COSY, HSQC and HMBC spectra are consistent with 11-deoxymogroside III confirmed the structure completely [16]. 


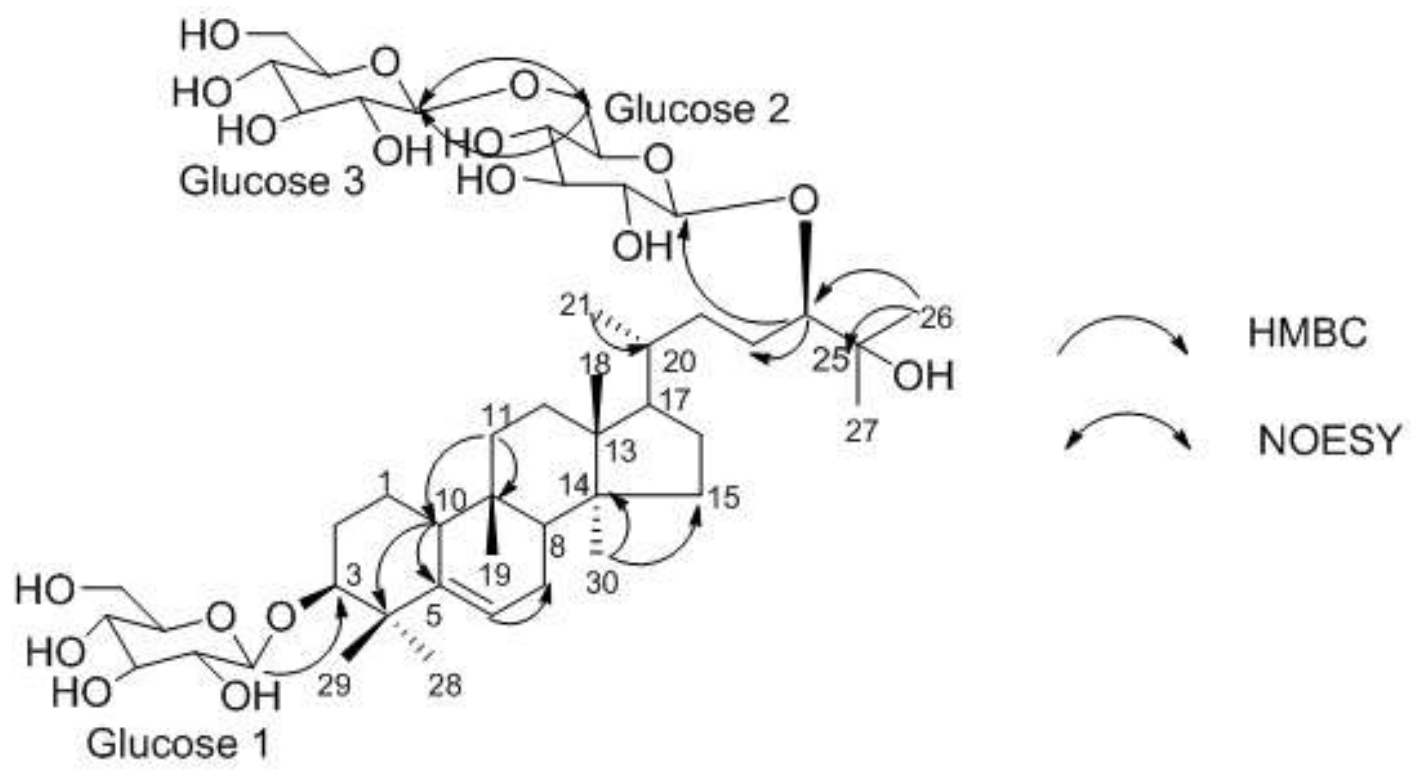

Figure 3: Key HMBC and NOESY correlation of 11-Deoxymogroside III (2)

\section{CONCLUSIONS}

Though the two isolated compounds are reported in the literature, the detailed NMR characterization has not been studied on the basis of 1D and 2D NMR as well as chemical studies. This is a compilation of the ${ }^{1} \mathrm{H}$ and ${ }^{13} \mathrm{C}$ NMR spectral data for the two compounds mogrosides III A2, and 11-deoxymogroside III in $\mathrm{CD}_{5} \mathrm{~N}_{5}$ based on the extensive 2D NMR spectroscopic data and chemical studies.

\section{REFERENCES}

[1]. Takemoto, T.; Arihara, S.; Nakajima, T.; Okuhira, M. Studies on the constituents of Fructus momordicae. I. Yakugaku Zasshi, 1983, 103, 1151-1154.

[2]. Takemoto, T.; Arihara, S.; Nakajima, T.; Okuhira, M. Studies on the constituents of Fructus momordicae. II. Yakugaku Zasshi, 1983, 103, 1155-1166.

[3]. Takemoto, T.; Arihara, S.; Nakajima, T.; Okuhira, M. Studies on the constituents of Fructus momordicae. III. Yakugaku Zasshi, 1983, 103, 1167-1173.

[4]. Yasushi, A.S.; Yuji, M.; Hiroshi, I.; Masaki, S.; Yoshihisa, N. Triterpene glycosides of Siraitia grosvenori inhibit rat intestinal maltase and suppress the rise in blood glucose level after a single oral administration of maltose in rats. J. Agric. Food Chem. 2005, 53, 2941-2946.

[5]. Chaturvedula, V.S.P.; Rhea, J.; Milanowski, D.; Mocek, U., Prakash, I. Nat. Prod. Commun. 2011, 6, 175-178.

[6]. Chaturvedula, V. S. P.; Mani, U.; Prakash, I. Diterpene glycosides from Stevia rebaudiana. Molecules. 2011, 16, 35523562.

[7]. Chaturvedula, V. S. P.; Prakash, I. A new diterpenoid glycoside from Stevia rebaudiana. Molecules. 2011, 16, 2937-2943.

[8]. Chaturvedula, V. S. P.; Prakash, I. Structures of the novel diterpene glycosides from Stevia rebaudiana. Carbohydr. Res. 2011, 346, 1057-1060

[9]. Chaturvedula, V. S. P.; Rhea, J.; Milanowski, D.; Mocek, U.; Prakash, I. Two minor diterpene glycosides from the leaves of Stevia rebaudiana. Nat. Prod. Commun. 2011, 6, 175-178.

[10]. Chaturvedula, V. S. P.; Prakash, I. Additional minor diterpene glycosides from Stevia rebaudiana. Nat. Prod. Commun. 2011, 6, 1059-1062.

[11]. Chaturvedula, V.S.P.; Clos, J.F.; Rhea, J.; Milanowski, D.; Mocek, U., DuBois, G.E.; Prakash, I. Phytochemistry Lett. 2011, 4, 209-212.

[12]. Chaturvedula, V. S. P.; Mani, U.; Prakash, I. Structures of the novel $\alpha$-glucosyl linked diterpene glycosides from Stevia rebaudiana. Carbohydr. Res. 2011, 346, 2034-2038.

[13]. Chaturvedula, V.S.P.; Prakash, I. Curcubitane Glycosides from Siraitia grosvenorii, J. Carbhydr. Chem, 2011, 30, 16-26.

[14]. Chaturvedula, V.S.P.; Prakash, I. Kaempferol glycosides from Siraitia grosvenorii, J. Chem. Pharm. Res., 2011, 3, 799804.

[15]. Tanaka, T.; Nakashima, T.; Ueda, T.; Tomii, K.; Kouno, I. Facile discrimination of aldose enantiomers by reversed-phase HPLC. Chem. Pharm. Bull. 2007, 55, 899-901.

[16]. Akihasa, T.; Hayakawa, Y.; Tokuda, H.; Banno, N.; Shimizu, N.; Suzuki, T.; Kimura, Y. Cucurbitane glycosides from the fruits of Siraitia grosvenorii and their inhibitory effects on Epstein-Barr virus activation, J. Nat. Prod., 2007, 70, 783-788. 